\title{
Yüksek Enerjili Klinik Lineer Hızlandırıcı Modellemesi ve Radyasyon Sızıntı Ölçümleri
}

\author{
Ümit Kara ${ }^{1 *}$, İskender Akkurt ${ }^{2}$ \\ ${ }^{1}$ Süleyman Demirel Üniversitesi, Isparta Sağllk Hizmetleri MYO, Tıbbi Görüntüleme Programı, Isparta, Türkiye (ORCID: 0000-0002-1435-9810) \\ ${ }^{2}$ Süleyman Demirel Üniversitesi, Fizik Bölümü, Isparta, Türkiye
}

(İlk Geliş Tarihi 21 Haziran 2019 ve Kabul Tarihi 17 Temmuz 2019)

(DOI: $10.31590 /$ ejosat.581029)

ATIF/REFERENCE: Kara, Ü. \& Akkurt, İ. (2019). Yüksek Enerjili Klinik Lineer Hızlandırıcı Modellemesi ve Radyasyon Sizıntı Ölçümleri. Avrupa Bilim ve Teknoloji Dergisi, (16), 707-712.

\section{Özet}

Günümüzde klinik radyasyon ve uygulamaları özellikle kanser ve türevi hastalıkların tanı ve tedavisinde sıkça kullanılmaktadır. Teknolojideki son gelişmeler ile birlikte klinik radyasyon kullanım alanları, cihaz ve modelleri her geçen gün yenilenmektedir. Dolayısı ile bu cihaz ve modellerin deneysel testleri ve ölçümleri için ilk aşamalarından birisi de simülasyon çalışmalarıdır. Bu anlamda özellikle radyasyonun simüle edilebilmesi ve gerekli hesaplamaları yapabilmek deneysel anlamda oldukça güçtür, bundan dolayı Monte Carlo yöntemi gibi matematiksel ve fiziksel problemleri aynı anda simülasyon tekniği ile birleştiren yazılımlar üretilmiştir. Bu çalışmada Monte Carlo yöntemini olarak MCNP kodu kullanılmış, cihaz ve oda için deneysel ölçümleri Süleyman Demirel Üniversitesi Tıp Fakültesi Hastanesi Radyasyon Onkolojisi Kliniğinde bulunan Klinik Lineer hızlandırıcı ile yapılmış ve elde edilen deney ve teorik sonuçlar korele edilmiştir. Çalışma sonucunda, seçilen yüksek enerjili klinik lineer hızlandırıcıda (18 MV) litaretürdeki çalışmalar, simülasyon ve deneysel sonuçlar karşılaştırmalı olarak incelenmiş, literatürdeki çalışmalar, deneysel ve simülasyon sonuçları arasında uyum gözlemlenmiştir.

Anahtar Kelimeler: Radyoterapi, Monte Carlo, Gama.

\begin{abstract}
Nowadays, clinical radiation and applications are used mostly in the diagnosis and treatment of cancer and derivative diseases. Recently advances in technology, clinical radiation usage areas, devices and models are renewed every day. Therefore, one of the first steps for experimental and measurements of these devices and models is simulation studies. In this situatuation, it is difficult to simulate the radiation and make the calculations experimentally, therefore, software that combines mathematical and physical problems such as Monte Carlo method with simulation technique has been produced. In this study, MCNP code was used as the Monte Carlo method and experimental measurements for the device and the room were measured in Süleyman Demirel University Faculty of Medicine Radiation Onclogy Department, clinical Linear Accelerator in Oncology Clinic and experimental and theoretical results were correlated. As a result of the study, the studies in the literature, simulation and experimental results were compared in selected high energy clinical linear accelerator (18 MV), and the studies in the literature.
\end{abstract}

Keywords: Radiotherapy, Monte Carlo, Gamma.

\footnotetext{
${ }^{1}$ Sorumlu Yazar: Süleyman Demirel Üniversitesi, Isparta Sağlı Hizmetleri MYO, Tıbbi Görüntüleme Programı, Isparta, Türkiye, ORCID: 00000002-1435-9810, umitkara@sdu.edu.tr
} 
European Journal of Science and Technology

\section{Giriş}

Radyasyon, kararsız bir çekirdek tarafindan yayılabileceği gibi yapay kaynaklar ile de üretilebilen parçacık veya elektromanyetik dalga formu şeklinde enerji taşınımıdır. Bu enerji formuna rutin hayatın içinde maruz kalmamız doğal bir süreçtir. Radyasyon, günlük hayatımızda gerek doğal yollardan, gerekse de gelişen teknoloji ile beraber yapay kaynaklardan yayınlanan biçimde insanoğlunun yaşamının bir parçası olmuştur. $\mathrm{Bu}$ nedenle, vücut, organ ve dokularımız radyasyonla etkileşime girebilmektedir. Tıbbi uygulamalarda iyonizan radyasyonun kullanımı tanısal radyoloji ve tedavi amaçlı olmak üzere iki ana gruba ayrıbilir. Tanısal olarak iyonizan radyasyon kullanımına örnek; röntgen, bilgisayarlı tomografi (BT) gibi cihazlar ile hastanın anatomik bilgilerinin elde edilmesi ve meydana gelen anomalilerin tespitidir. Tedavi için amaçlı radyasyon kullanımında ise radyoterapi kliniklerinde LINAC gibi cihazlarda elde edilen yüksek enerjili ışımalar ile karsinom dokuların hedeflenmesi, izlenen tedavi programına göre ayarlanan dozlarda karsinom dokuların bertaraf edilmesi sağlanmaktadır. Tıbbi alandaki radyasyon uygulamaları ile görüntü elde etme işlemleri ülkemizde çoğunlukla diyagnostik radyoloji ve nükleer tıp birimlerinde gerçekleştirilirken, karsinojen hücre veya tümörleri yok ederek tedavi uygulama işlemleri ise radyasyon onkolojisi birimlerinde gerçekleştirilmektedir. Radyoterapi uygulamalarında hastada bazı yan etkiler meydana geldiği bilinmektedir. Bu yan etkiler; halsizlik, şişme, ağırlık hissi, derinin güneş yanığı rengi alması gibi belirtilere sahiptir. Bir radyoterapi işlemi, cerrahi operasyonlardan sonra sağ kalma olasıllğı olan kanser hücrelerinin öldürülmesini sağlamak, kanserli bölgedeki canlı hücre sayısını azaltarak tümörün tekrarlanma riskini azaltmak, uygulanan bölge dışındaki lenf bezi yayılımlarını azaltmak (Mümkün olduğunca bitirmek) ve klonojenik hücrelerin yayılma ihtimalini azaltmak amacıyla uygulanır. Bölgesel mikroyayılımlar, eşdeğer radikal cerrahi nedeniyle oluşan anatomik ve bazen fizyolojik kayıplar olmadan radyoterapi ile tedavi edilebilir (Chao vd., 2004).

Kanser tedavisinde, birçok tedavi seçeneği bulunmasına rağmen bunların içinde radyoterapi ayrı bir yere sahiptir. Radyoterapi işlemlerinde mevcut olan iyonizan radyasyon kullanımından dolayı, farklı türde radyasyondan korunma gereklilikleri gerek hasta gerekse de çalışanlar için ortaya çıkmıştır. Radyoterapide önemli noktalardan birisi de tedavi için gönderilen ışınların karakteristiği ve bunların oluşma safhasıdır. Bu çalışmalar genelde deneysel veya teorik olabilmektedir. Tıbbi uygulamalarda yapılan deneysel yapılan çalışmalar çoğu zaman hasta sağlığı ve risk açısından mümkün olmayacağı gibi çoğu zaman da doğruluğunun teyit edilmesi açısından tek başına yetersiz kalabilmektedir. Diğer yandan, deneysel çalışmaların kurulumu ve uygulanması işlemi de çoğu zaman ekonomik açıdan bir maliyeti de beraberinde getirmektedir (Aydogmus Erik v.d., 2019) . Tüm bu sebeplerden dolayı, matematiksel modellemeler ve farklı simülasyon tekniklerinin günümüzde yaygın kullanımı sayesinde elde edilmesi zor olan geometrik yapılan, cihaz modellemeleri ve hasta fantomları günümüzde kolayca yapılabilmektedir (Tekin v.d.,2018, Tekin v.d., 2019, Kavaz v.d., 2019). Ahnesjö ve ekibinin 1994 yllındaki çalışmada, küçük alanlarda önem taşıyan, düzleştirici filtre ve primer kolimatörün, verim oranlarında yaklaşık \% 12 oranında katkı sağladığı ortaya çıkarmıştır. Zhu ve ekibi ise 1995 yılındaki çalışmasında, kafa saçılması faktörüne etki eden birçok farklı durum olduğunu ortaya çıkarmış ayrıca fotonların hızlandırıcı kafasındaki bazı yapılardan saçıldıklarını gözlemlemiştir. Siebers ve ekibi ise 1999 yılındaki çalışması ile insan vücudunda birden çok farklı organ ve dokudan oluşmasına karşın günümüzde klinik radyoterapi için suda yüzeyinde bırakılan doz hesaplamaları temeline dayanmaktadır. Monte Carlo doz hesaplama algoritması özellikle doku, akciğer ve kemiklerden oluşan hasta ortamlarında da yüksek kesinlikte doz hesaplamalarında sonuç verebilmektedir. Bu çalışmada ise etkileşimin olduğu malzemede 6 ve $18 \mathrm{MV}$ 'luk foton demetlerinin doz oranları birincil elektron spektrumlarının ortalama durdurma gücünün hesaplanmasıyla elde edilmiş bulgulardır. Barquero ve ekibinin 2005 yıllında yaptıkları çalışmada ise Monte Carlo simülasyon tekniği olarak MCNP kodunu kullanmış ve hastalara ulaşan foto nötron doz değerlerini araştırmışlardır. Çalışmada fantom ile dört alan ve tedavi yöntemi uygulanmışlardır. Özellikle hastanın epidermis tabakasına yakın bölgedeki tedavi alanı içindeki organ ve dokularda foto nötron doz oranlarının daha yüksek olduğunu bulmuştur. Bu sonuca bağlı olarak, uzak organlardan elde edilen edilen nötron dozlarında ve derin organlardaki eşdeğer nötron dozları için iyi bir sonuç elde etmişlerdir.

\section{Materyal ve Yöntem}

Monte Carlo simülasyon metodu, olasılıklar dahilindeki durumları simüle etmeye yardım eden ve farklı algoritma dillerine sahip istatistiksel bir teknik ile çalışan bir yapıdır (Kavaz v.d., 2019b, Tekin v.d., 2019b). İlk ortaya çıkış süreci araştırmacılar tarafından özellikle deneysel amaçlı çalışmaları simüle etmek için kullanılmak üzere keşfedilmiş olup, sonraları tıp, enerji, malzeme araştırmaları v.b. gibi birçok farklı alanlarda kullanılmaya başlanmıştır (Sayyed v.d., 2019) . Tıbbi alanda Monte Carlo simülasyon metodunun kullanımı, medikal fizik araştırmalarında da dünyaca kabul görmüş ve özellikle radyasyon etkileşimleri gibi karmaşık yapıya sahip problemlerin çözümünde oldukça kullanışlı bir yöntem haline gelmiş̧ir. Bu çalışmada, deneysel çalışma için Süleyman Demirel Üniversitesi Radyasyon Onkolojisi birimi Klinik Lineer Hızlandırıcı Ünitesi kullanılmıştır. Deneysel ölçüm gereçleri ve kontrolleri Radyasyon Onkolojisi biriminde gerçekleştirilmiştir. Kalite kontrol işlemlerinde kullanılan iyon odası, dozimetre, barometre gibi hassas cihazların kalibrasyonları, ölçümlere başlamadan önce gerçekleştirilmiştir. Elektrik ve mekanik kontroller yapıldıktan sonra, dozimetrik kalite kontrolleri ve kalibrasyonu yapılmıştır. Doz ölçüm çalışmaları, katı fantomda gerçekleştirilmiştir ayrıca klinik radyasyon onkoloji hastalarının üzerinde doz dağılımlarını ölçmek oldukça güç bir durumdur. Dolayısı ile ölçümler için bahsedilen fantomlar kullanılmıştı. Fiziki özellik olarak ise yoğunluğu yaklaşık olarak $1,04 \mathrm{~g} / \mathrm{cm}^{3}$, elektron yoğunluğu $3,43.10^{23}$ e $/ \mathrm{cm}^{3}$ olan RW3 katı su fantomu özellikleri $\% 2 \mathrm{TiO}_{2}$ içeren beyaz polystrenden $30 \times 30 \mathrm{~cm}^{2}$ boyutlarında monitor kalibrasyonları ve derin doz ölçümlerini katı fantom içerisinde yapılabilmesine olanak sağlayan, yüksek enerjili foton ve elektron dozimetresine uygun bir fantomdur ayrıca $1 \mathrm{~mm}$ aralıklarla $30 \mathrm{~cm}$ derinliğe kadar ölçüm imkanı akrilik veya su eşdeğeri RW3 malzemeden yapılmıştır. Kalınlık tolerans değeri $\pm 0.1 \mathrm{~mm}$ dir. Ayrıca fantom olarak kullanılma diğer biri sebebi ise suyun yoğunluğu, kas ve yumuşak doku yoğunluğuna çok yakındır. Bu yüzden, temel doz dağılımları için su kullanılır. Ölçüm için su ortamının seçilmesinin diğer bir sebebi de kolayca tekrarlanabilir olmasındandır. Suda ölçüm yapmanın en önemli dezavantajı kullanılacak olan iyon odası veya diyotların su geçirmez olması gerekliliğidir. Aşağıda orjinal plan, iki boyutlu ve üç boyutlu çizimleri verilmiş̧ olan Şekil 1 ve Şekil 3'de verilen 
numaralar ile ifadelendirilmiş olan deneysel ölçüm noktaları belirlenmiştir. Ayrıca deneysel gama ölçümler için Polimaster marka 1703mo-1b model cihaz kullanılmıştır (Şekil 2).
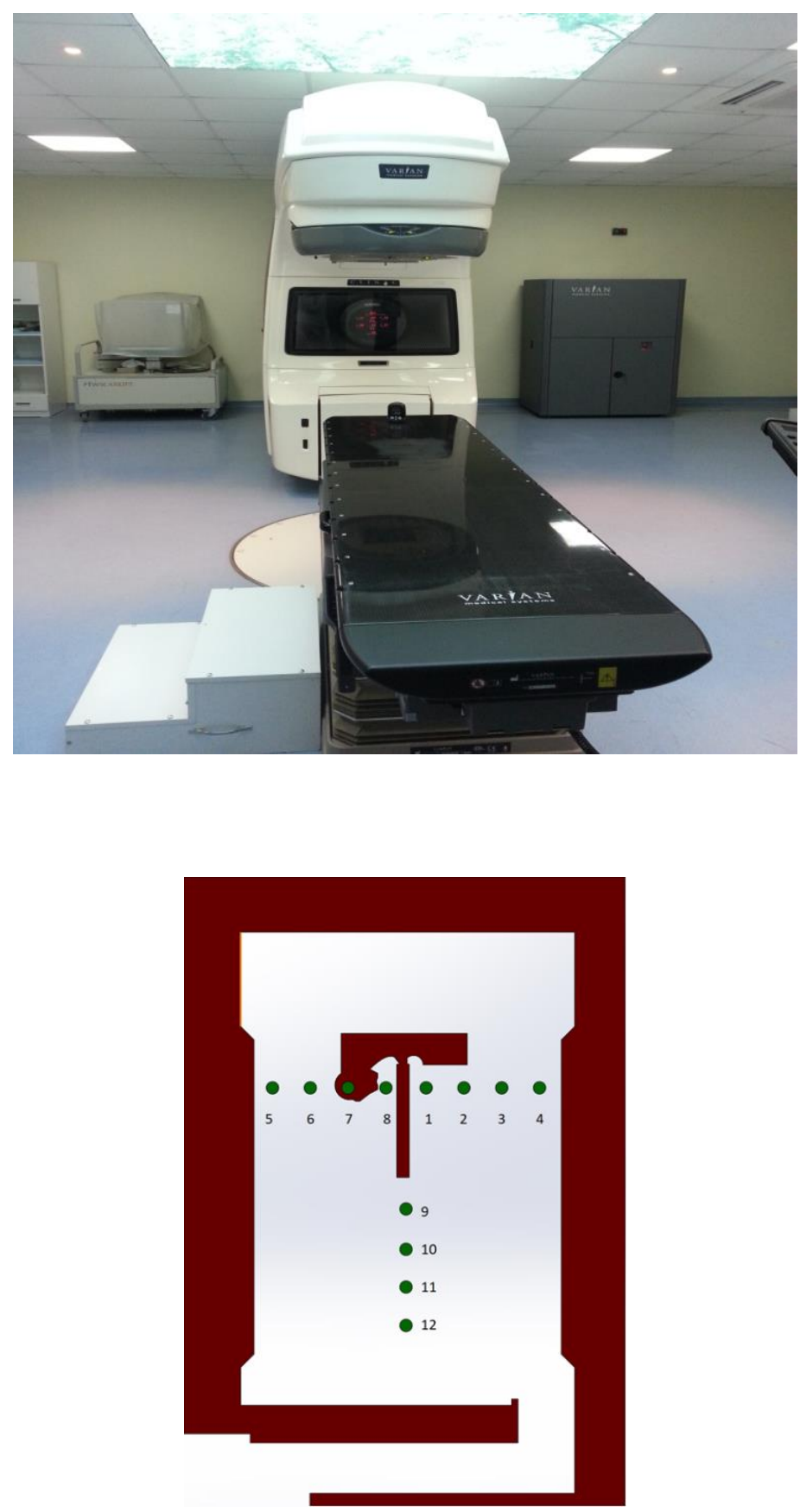

Şekil 1. Kullanılan klinik lineer hızlandırıcı, tedavi oda planı ve şematik olarak ölçüm noktaları

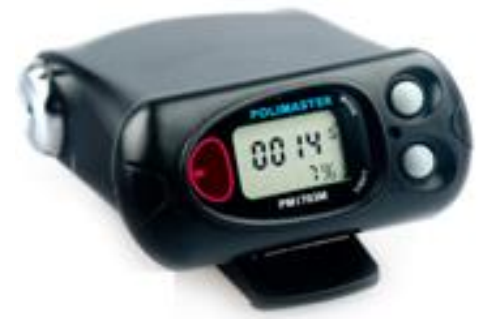

Şekil 2. Deneysel ölçüm için kullanılan gama dedektörü (Polimaster 1703mo-1b)

Çalışmanın bir diğer aşaması olan Monte Carlo simülasyonları da MCNP kodu kullanılarak gerçekleştirilmiştir. MCNP, radyasyon taşınımını tüm fiziksel süreçleri ve etkileşimleri göz önüne alarak gerçekleştiren ve simüle eden kullanıcı dostu bir kod olarak 
bilinmektedir (Abouhaswa v.d., 2019). MCNP foton, elektron, nötron gibi iyonize olan radyasyon türlerinin maddesel ortamlardan geçişlerini Monte Carlo yöntemini kullanarak modelleyen bir simülasyon programıdır (Briesmeister, 1997). MCNP kodu karmaşık parçacık geçişini modellemede sağlıklı bir şekilde kullanılabilir. Çünkü üretilen belirli aralıktaki rastgele değerlerle birlikte sürekli etki kesiti verisini kullanır.

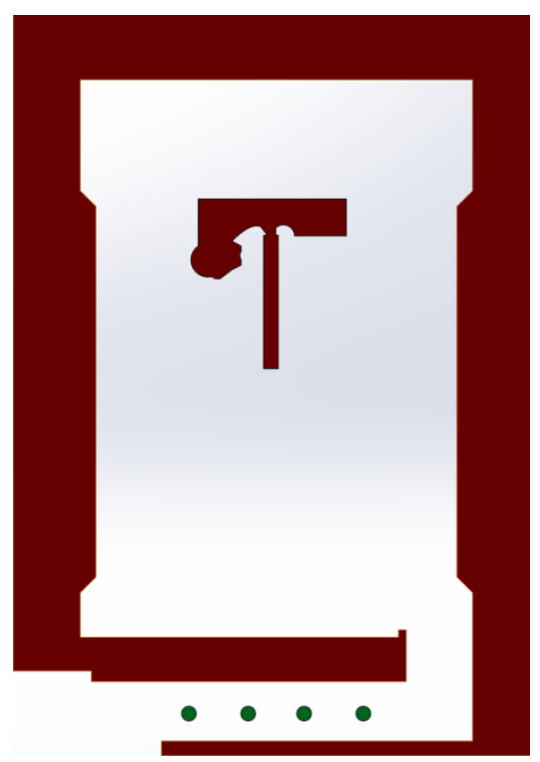

Şekil 3. Kullanılan klinik lineer hızlandırıcı koridorunda yer alan ölçüm noktalarının şematize edilmiş hali

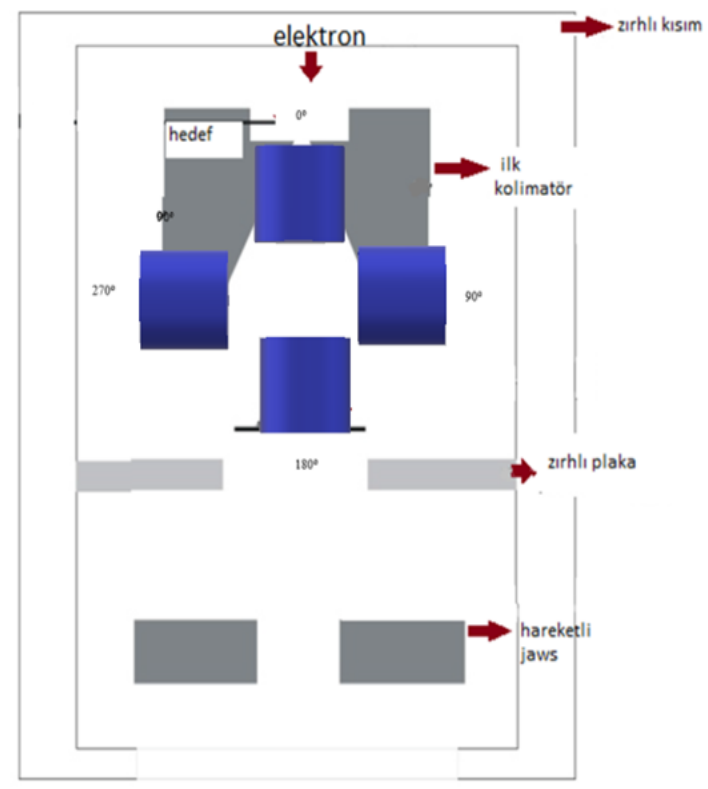

Şekil 4. Monte Carlo yöntemi ile (MCNP) simüle edilen klinik medikal lineer hızlandırıcı kafası ve farklı açılardaki kafa şematizesi

\section{Araştırma Bulguları}

Foton radyoterapi kanser tedavisinde günümüzde sıkça kullanmakta olan önemli bir yöntemdir. Dolayısıyla radyoterapi ünitelerinde radyasyon kirliliği ve bunların belirlenmesi önemli bir faktördür. Yapmış olduğumuz bu çalışmada Süleyman Demirel Üniversitesi, Araştırma ve Uygulama Hastanesi, Radyasyon Onkolojisi, Radyoterapi ünitesinde teorik ve deneysel ölçümleri gerçekleştirmeyi hedefledik. Çalışmanın amacı, radyoterapi ünitelerindeki gama doz sızıntılarının tespiti ve önlemleridir. Dünyada ve Türkiye'de günümüz popüler konuları arasında yer alan doz sızıntıları ve bunların etkileri konusunda bu temel amaca yönelik olarak yüksek enerji değerlerine sahip olan klinik lineer hızlandırıcılarda değişik dozlardaki ışınlamalar için gama dozu ölçümleri ve elde edilen doz ölçümlerinin teorik hesaplamalarla karşılaş̧ırılması çalışmalarını gerçekleştirilmiştir. Bu deneysel ve teorik ölçümlerde ortaya çıkan sonuçlar aşağıdaki gibidir.

Şekil 5. ve iki boyutlu modellenen planlarda da (Bir - Dört numara arası) görülebileceği gibi, doz uzaklık grafiği için merkez ekseninden uzaklaştıkça azalmaktadır. Şekil 5. ve iki boyutlu modellenen planlarda da (Beş - Sekiz numara arası) görülebileceği gibi, doz uzaklık grafị̆i için merkez ekseninden uzaklaştıkça azalmaktadır. Şekil 5. ve iki boyutlu modellenen planlarda da (Dokuz - Oniki numara arası) görülebileceği gibi, doz uzaklık grafiği için merkez ekseninden uzaklaştıkça azalmaktadır. 


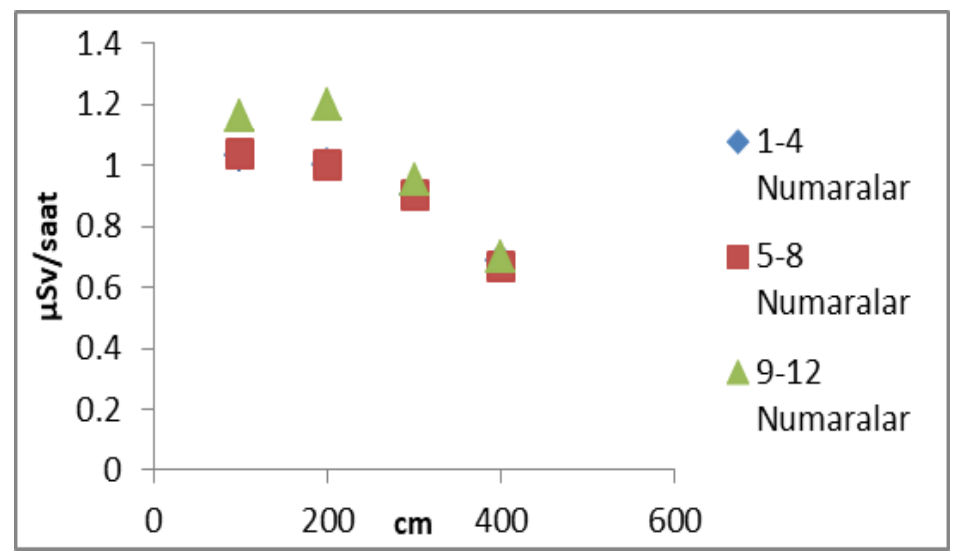

Şekil 5. Deneysel ölçüm gama doz dă̆gllım grafiği (1-12 numaralar)

Şekil 6. ve iki boyutlu modellenen planlarda da görülebileceği gibi, doz uzaklık grafiği için merkez ekseninden uzaklaştıkça azalmaktadır. Ayrıca çalışmanın önceki literatür çalışmaları ile uyumlu bir şekilde korelasyon grafiği ile de uyumlu olduğu ortaya çıkmıştır.

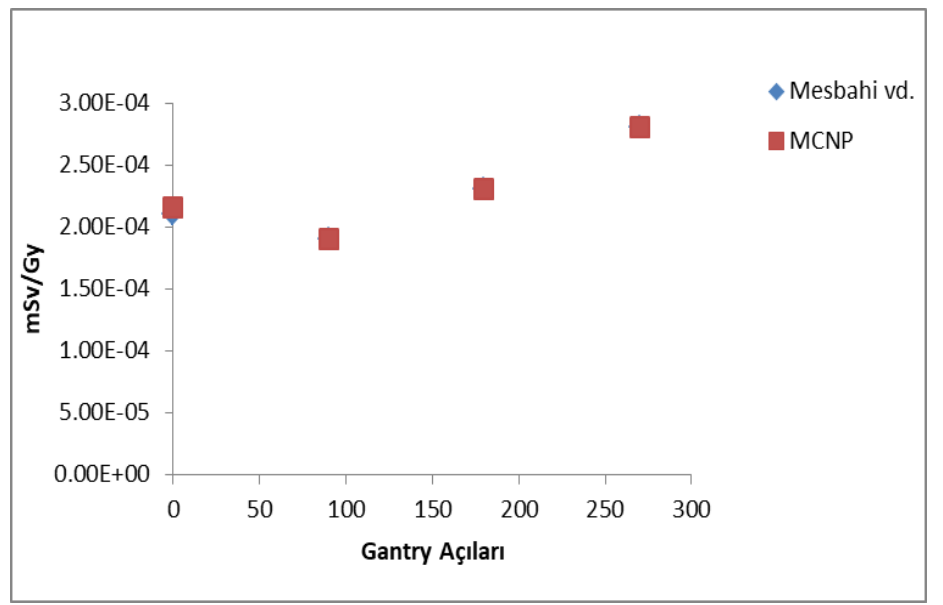

Şekil 6. Monte Carlo yöntemi (MCNP) ile simüle edilen klinik medikal lineer hızlandırıcı koridor doz değişim grafĭgi

Şekil 7. ve iki boyutlu modellenen planlarda da görülebileceği gibi, doz cihaz sırası ile kafa açışlarına göre $(0.90,180,270)$ artmaktadır. Ayrıca çalışmanın önceki literatür çalışmaları ile uyumlu bir şekilde korelasyon grafiği ile de uyumlu olduğu ortaya çıkmıştır.

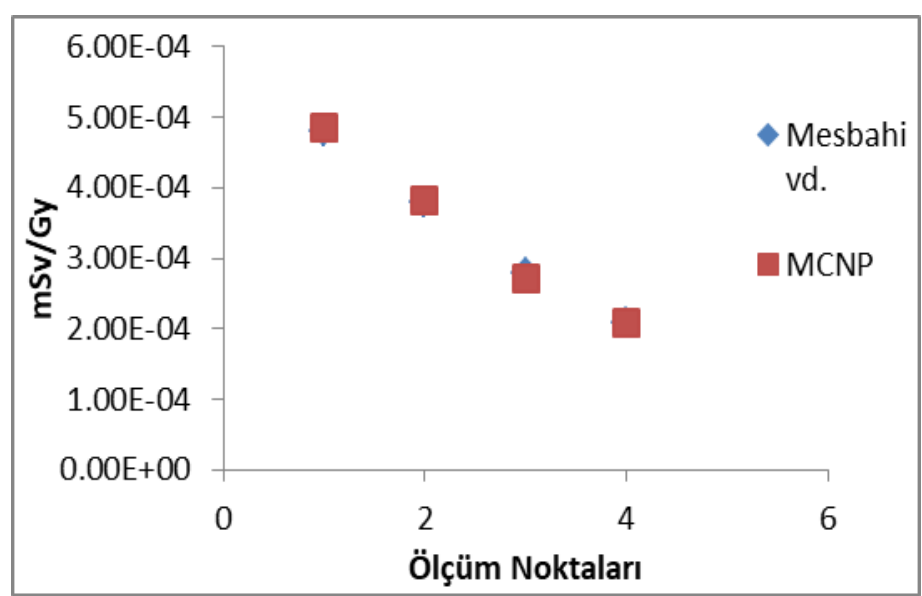

Şekil 7. Monte Carlo yöntemi (MCNP) ile simüle edilen klinik medikal lineer hızlandırıcı kafası farklı açılardaki (0, 90, 180, 270) doz değişim grafĭgi

Bu çalışmayla beraber ortaya çıkan durumlardan bir tanesi de aslında radyoterapi ile beraber ortaya çıkan doz kirliliğidir. Dolayısıyla hasta tedavi için gelmiş bulunduğu radyoterapide aynı zamanda ek olarak kirlilikten dolayı radyasyon sızıntısına da maruz 
kalmaktadır. Bu durum tedavi için önem arz etmektedir. Çalışmamızda da kullanılan model ya da metotlar kullanılarak ve geliştirilerek rutin klinik tedavi işlemlerinde doz değerlerinin tahminleri yapılabilir. Ayrıca modelleme için kullanılan MC metodu ile radyoterapi cihazları için yeni modellerin tasarlanması gerçekleşebilmektedir. Yapmış olduğumuz çalışmada $18 \mathrm{MeV}$ 'de oluşan doz değerleri için farklı noktalarda ve kafa açılarında ölçümler alınmıştır.

\section{Tartışma ve Sonuç}

Yapmış olduğumuz çalışmada rutinde de kullanılan ve deneysel ölçümlerini de almış olduğumuz klinik lineer hızlandırıcı cihazı modelleme işleminde cihazın da geometrisinden yararlanılmıştır. Radyoterapi ünitesinde, özellikle de hasta tedavi aşamasında farklı türde radyasyonlar oluşabilmektedir. Bunlar; birincil demet, saçılan radyasyon ve sızıntı radyasyonu gibi etkenlerdir. Özellikle 18 MV de çalışan klinik lineer hızlandırıcılar tarafından ortaya çıkan nötron dozu ile nötron yakalama reaksiyonları sonucunda ortaya sekonder gama 1şınları oluşabilmektedir. Bu sekonder radyasyon kontaminasyonu hastanın ve de radyasyon çalışanlarının aldığı ortlama günlük dozu arttırabilmektedir. Dolayısı ile radyasyon çalışanlarının tedavi sırasında odasında bulunmamasına rağmen, sızıntı ile ortaya çıkan nötron ve foton kaynaklı radyasyonu kontaminasyonu ile çalışanlar bu duruma maruz kalabilmektedirler.

Ayrıca olası kontaminasyon önlemek için tasarlanan kapılar ağır bir yapıya sahip oldukları için ve olası kullanım zorluğundan dolayı pek tercih edilmemektedirler. Bu açıdan özellikle klinik tasarımlarda radyoterapi odalarında şaşırtma koridoru dizayn edilmektedir. $\mathrm{Bu}$ anlamda literatüre katkı vermek için özellikle gama dozları ölçümleri ilgili klinikte yapılmıştır ve saçılan fotonların medikal hızlandırıcı kafası ve bileşenleri ile tekrar etkileşime geçmesinden dolayı olduğu kanaatına varılmıştır. Fakat bütün ölçüm noktalarında ortak olan durum ise kafa merkezinden uzaklaştıkça doz oranlarındaki azalma olmuştur. Radyoterapi ünitesi için artan gama varlığı hasta dozuna ek bir doz alındığı hesaba katılması gerektiği ve tedavi sırasında da ikincil kanser riski hesaplanması ve çalışan sağlık personeli radyasyon güvenliği konusu mutlaka göz önüne alınmalıdır. Yapmış olduğumuz ölçümlerde diğer bir önemli kısmı ise koridor doz değerlerinin istenen değerlerde ortaya çıkması olmuştur.

\section{Referanslar}

Chao Clifford K.S., Perez Carlos A., Brady Luther W. (2004). Radyasyon Onkolojisi Tedavi Kararları. Gemici C., Mayadağlı A., Parlak C., Nobel Tip Kitabevleri, İstanbul, 112-521.

Ahnesjö, A. (1994). Analytic modeling of photon scatter from flattening filters in photon therapy beams. Med. Phys., 21, $1227-1235$.

Zhu T.C., Bjärngard B.E. (1995). The fraction of photons undergoing head scatter in X-ray beams. Phys Med Biol. 40:1127-1134.

Siebers JV, Keall PJ, Libby B, Mohan R. (1999). Comparison of EGS4 and MCNP4b Monte Carlo codes for generation of photon phase space distributions for a Varian 2100C. Phys Med Biol. 44:3009-26.

Mesbahi, A., Fix, M., Allahverdi, M., Grein, E. and Garaati, H. (2005). Monte Carlo calculation of Varian 2300C/D Linac photon beam characteristics: a comparison between MCNP4C, GEANT3 and measurements. Appl. Radiat. Isot. 62(3), 469-477

Mesbahi, A. and Nejad, F. S. (2008). Monte Carlo study on a flattening filter-free 18-MV photon beam of a medical linear accelerator. Radiat. Med. 26(6), 331-336.

Mesbahi, A. (2009). A Monte Carlo study on neutron and electron contamination of an unflattened 18-MV photon beam. Appl. Radiat. Isot. 67(1), 55-60.

Mesbahi, A., Keshtkar, A., Mohammadi, E. and Mohammadzadeh, M. (2010). Effect of wedge filter and field size on photoneutron dose equivalent for an $18 \mathrm{MV}$ photon beam of a medical linear accelerator. Appl. Radiat. Isot. 68(1), 84-89.

McGinley, P. H. (1998). Shielding techniques for radiation oncology facilities Madison, WI. Medical Physics Publishing.

A. Aydogmuş Erik, E.Kavaz, Serkan Ilkbahar, U.Kara, C. E.Erik, H.O. Tekin. (2019). Structural and photon attenuation properties of different types of fiber post materials for dental radiology applications. Results in Physics 13 (2019) 102354. $<$ https://doi.org/10.1016/j.rinp.2019.102354>

H.O. Tekin, M.I. Sayyed, T.T. Erguzel, M. Karahan, O. Kilicoglu, A. Mesbahi, U. Kara. (2018). Investigation of Water Equivalance and Shielding Properties of Different Solid Phantoms using MCNPX Code. Digest Journal of Nanomaterials and Biostructures. Vol. 13, No. 2, April-June, p.551-562 .

H.O. Tekin, E. Kavaz, Athanasia Papachristodoulou, M.Kamislioglu, O.Agar, E.E.Altunsoy Guclu, O.Kilicoglu, M.I. Sayyed. (2019). Characterization of $\mathrm{SiO} 2-\mathrm{PbO}-\mathrm{CdO}-\mathrm{Ga} 2 \mathrm{O} 3$ glasses for comprehensive nuclear shielding performance: Alpha, proton, gamma, neutron Radiation. Ceramics International. <https://doi.org/10.1016/j.ceramint.2019.06.168> 